\title{
A EDUCAÇÃO EM SAÚDE PARA USUÁRIOS HIPERTENSOS: PERCEPÇÕ̃ES DE PROFISSIONAIS DA ESTRATÉGIA SAÚDE DA FAMÍLIA
}

\section{Health education for hypertensens: perceptions of professionals of the Family Health Strategy}

Joel Dácio de Souza Maia • Bacharel e Licenciado em Enfermagem e Mestre em Saúde da Família (RENASF/UFRN). E- mail: joel.dacio@hotmail.com

Alexandre Bezerra Silva • Bacharel e Licenciado em Enfermagem e Mestre em Saúde da Família (RENASF/UFRN).E- mail: alexandre_enfe@hotmail.com

Ricardo Henrique Vieira de Melo - Mestre em Saúde da Família (RENASF/UFRN). Dentista da Estratégia Saúde da Família de Nazaré (Natal/RN). Preceptor do Petgraduasus e da Residência Multiprofissional em Saúde (UFRN). Facilitador Pedagógico do Programa de Educação Permanente em Saúde da Família (PEPSUS/UFRN). E-mail: ricardohvm@gmail.com

Maísa Paulino Rodrigues • Doutora em Ciências da Saúde e Docente do Programa de Pós-Graduação em Saúde Coletiva (UFRN). E-mail: maisarodrigues13@gmail.com

Antônio Medeiros Júnior • Doutor em Ciências da Saúde (UFRN); Docente do Departamento de Saúde Coletiva (UFRN); docente do Mestrado Profissional em Saúde da Família no Nordeste, da Rede Nordeste de Formação em Saúde da Família (RENASF). E-mail: soriedemjunior@gmail.com

Autor responsável pela correspondência:

Joel Dácio de Souza Maia. Bacharel e Licenciado em Enfermagem e Mestre em Saúde da Família (RENASF/UFRN). E- mail: joel.dacio@hotmail.com 


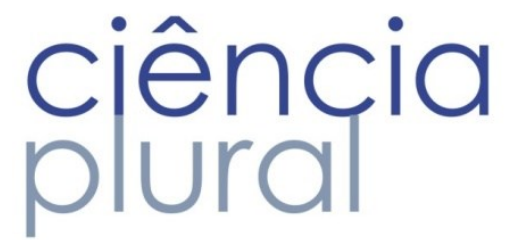

RESUMO

Introdução: As equipes da Estratégia Saúde da Família têm um papel primordial no enfrentamento das doenças crônicas e na busca de melhoria da qualidade de vida, pela transformação social. Objetivos: Esta pesquisa qualitativa buscou analisar as percepções de profissionais da Estratégia, em um município nordestino, acerca da prática da educação em saúde direcionada aos portadores de Hipertensão Arterial Sistêmica e apreender as concepções dos sujeitos sobre a importância da Educação Popular em Saúde e da formação de grupos de autocuidado para a promoção de saúde. Métodos: Foi realizado um estudo exploratório do tipo compreensivo-interpretativo, com a construção dos dados a partir de entrevistas abertas e análise temática de conteúdo. Resultados: Emergiram quatro categorias de análise: a percepção dos profissionais sobre a educação em saúde; as práticas de educação em saúde desenvolvidas para usuários hipertensos; os entraves para o desenvolvimento das ações de educação em saúde; e a formação de grupos de autocuidado para usuários hipertensos. Os achados apontaram que as ações educativas são desenvolvidas nos moldes tradicionalistas, utilizando largamente palestras como ferramenta pedagógica. Constatou-se a necessidade de estímulo ao empoderamento e protagonismo dos usuários, para exercitar uma postura ética, cidadã, motivadora para o controle social e a corresponsabilização. Conclusão: Recomenda-se que as ações de educação em saúde, aliadas à formação de grupos de autocuidado, sejam norteadas pelas diretrizes de uma prática pedagógica libertadora, enquanto estratégia para a construção de conhecimento socialmente relevante, ancorada na reflexão, dialogicidade e intervenção crítica em si e no mundo.

Palavras-Chave: Educação em Saúde; Hipertensão; Estratégia Saúde da Família.

\section{ABSTRACT}

Introduction: The Family Health Strategy teams have a primary role in coping with chronic diseases and in the quest for improvement in quality of life, through social transformation. Objectives: This qualitative study sought to analyze the perceptions of professionals of the Health Strategy, in a Brasilian municipality, about the practice of health education aimed at patients with Systemic Hypertension; and to apprehend the subjects' conceptions about the importance of Popular Education in Health and the formation of self-care groups for health promotion. Methods: An exploratory study of the comprehension-interpretative type was carried out, with the construction of the data from open interviews and content thematic analysis. Results: Four categories of analysis were found: the professionals' perception about health education; the health education practices developed for users with hipertension; the obstacles to the development of health education actions; and the formation of self-care groups. The findings pointed out that educational actions are developed along traditionalist lines, using lectures as a pedagogical tool. It was verified the need to stimulate the empowerment and protagonism of users, to exercise an ethical, citizen, motivating position for social control and co-responsibility. Conclusion: It is recommended that the actions of health education, combined with the formation of groups of people aiming at self-care, be guided by the guidelines of a liberating pedagogical practice, as a strategy for the construction of socially relevant knowledge, anchored in reflection, and critical intervention.

Keywords: Health Education; Hypertension; Family Health Strategy. 


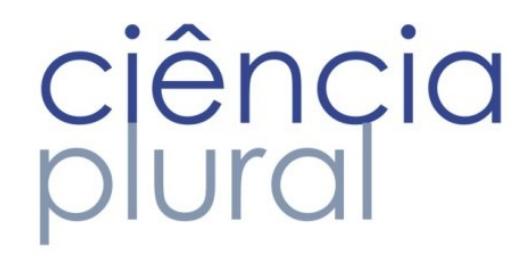

Introdução

$\mathrm{Na}$ atualidade, a hipertensão arterial sistêmica (HAS) apresenta alta morbimortalidade, com reflexos na qualidade de vida das pessoas, o que reforça a importância de sua prevenção e diagnóstico precoce. 0 diagnóstico não requer tecnologia sofisticada, e a doença pode ser tratada e controlada com mudanças no estilo de vida, com medicamentos de baixo custo e de poucos efeitos colaterais, comprovadamente eficazes e de fácil aplicabilidade na Atenção Primária à Saúde1.

A HAS ocorre em concomitância com outras doenças crônicas, a exemplo da diabetes mellitus (DM), cuja possibilidade de associação é da ordem de 50\%. Este fato requer o manejo das duas doenças no mesmo usuário, agravado pelo fato de que sua simultaneidade potencializa o dano micro e macro vascular decorrente, aumentando a morbidade cárdio-cérebro-vascular. A associação habitual e perigosa das duas patologias frequentemente maximiza essa agregação a ponto de a HAS ser a maior determinante da ocorrência de eventos cardiovasculares em pacientes diabéticos do tipo II e é duas vezes mais prevalente em indivíduos diabéticos 2,3 .

A probabilidade do surgimento de hipertensão arterial sistêmica é maior em mulheres e em pessoas de raça não branca. Um fator interessante é a associação inversa entre o diagnóstico de HAS com o nível de escolaridade, que aponta para a possibilidade de as pessoas com um grau de instrução mais elevado terem mais probabilidade de desenvolver HAS. Enquanto 34,4\% das mulheres com até 8 (oito) anos de escolaridade referiram diagnóstico de HAS, a mesma condição foi observada em apenas 14,2\% das mulheres com 12 ou mais anos de escolaridade. Para os homens, o diagnóstico da doença foi menos frequente nos que estudaram de 9 (nove) a 11 (onze) anos ${ }^{4}$.

As equipes da Estratégia Saúde da Família (ESF) têm um papel primordial no enfrentamento da HAS, pois, devido à sua conformação, à estrutura, à proposta de trabalho/ação e à proximidade com as pessoas, dispõe de meios e de instrumentos para o desenvolvimento de ações que sejam eficientes e consigam melhorar a saúde dessas pessoas de modo geral. Destaca-se aqui a promoção e a educação em saúde, que se configuram como instrumentos capazes de auxiliar significativamente os atores envolvidos em práticas de saúde, nas quais a população enfrenta situações de opressão, de desigualdades sociais e econômicas, insuficiência e inadequação de habitação, restrições de direitos sociais, e ampliam-se as necessidades de saúde individuais e coletivas. Neste sentido, a busca criativa por soluções de problemas de forma cooperativa potencializa a dinâmica dos espaços comunicativos, na produção e expressão dos 


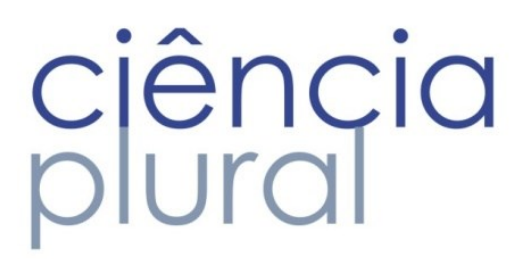

anseios, desejos e partilhas das histórias de vida, durante as intervenções para o controle das doenças crônicas ${ }^{5}$.

Não temos dúvida que a formação de grupos representa uma proposta adequada para efetivar a educação em saúde como instrumento de transformação social e melhoramento da saúde e da qualidade de vida. Para isso, é necessário revisitar o processo de organização das instituições e da comunidade, nas situações concretas demandadas pela população e criar as interações subjetivas reflexivas e singulares entre gestores, profissionais e usuários do território, inerentes ao desenvolvimento dos grupos, considerando as teorizações da promoção e de educação à saúde como uma alternativa operacional necessária para afirmar os preceitos da integralidade na prática6.

A educação em saúde não deve ser a do tipo palestras, aulas e repasse de conhecimento, em que um personagem é detentor do saber, e os demais são meros espectadores e captadores das informações repassadas, mas a que empodera os sujeitos participantes e lhes concede condições para gerenciar seus hábitos cotidianos, seus cuidados e sua vida. Em outras palavras, são práticas educativas que, de fato, emancipem os sujeitos, estimulem-nos a buscar a própria autonomia e os coloquem, através do diálogo, no centro do processo de construção do conhecimento?.

Nessa linha de reflexão, duas estratégias de prevenção são consideradas importantes na prevenção primária à Hipertensão Arterial Sistêmica (HAS): a populacional e a dirigida a grupos de risco. A primeira defende a redução da exposição populacional a fatores de risco, principalmente ao consumo de sal. 0 profissional poderá atuar nessa estratégia por meio de ações educativas coletivas com a população em geral para orientar a restrição à adição de sal na preparação de alimentos. A segunda, refere-se às estratégias dirigidas a grupos de riscos que propõe intervenção educativa, com foco para tratamento não medicamentoso da HAS e promoção de mudanças no estilo de vida8.

Com base nessas reflexões surgiram os seguintes questionamentos: qual a concepção dos profissionais da ESF acerca das práticas de educação em saúde direcionadas aos hipertensos? Qual a percepção deles sobre a relevância da formação de grupos de autocuidado para enfrentamento da hipertensão? Nesse contexto, o estudo buscou analisar as percepções de profissionais da Estratégia de Saúde da Família, em um município nordestino, acerca da prática da educação em saúde direcionada aos portadores de Hipertensão Arterial Sistêmica (HAS); e apreender as concepções dos sujeitos sobre a importância da Educação Popular em Saúde e da formação de grupos de autocuidado para a promoção de saúde. 


\section{ciência plural}

\section{Metodologia}

Trata-se de um estudo do tipo exploratório e descritivo, de natureza qualitativa na intenção de descrever, compreender e explicar profundamente suas nuances a partir de valores individuais, crenças, hábitos opiniões e representações ${ }^{9}$.

O cenário do estudo foi a Unidade de Saúde da Família Joana Cacilda de Bessa, localizada na zona urbana da cidade de Pau dos Ferros, na região do Alto Oeste do Rio Grande do Norte, Brasil. 0 município tem uma população de 29.954 habitantes ${ }^{10} \mathrm{e}$, segundo o Sistema de Informação da Atenção Básica, possuía doze equipes de saúde da família, três localizadas na zona rural e nove, na urbana, durante o período de realização da investigação. 0 total de hipertensos cadastrados no município era de 1.476, sendo que, na ESF foco dessa pesquisa, o número de usuários com HAS era 485, maior prevalência do município.

Participaram do estudo: trabalhadores da ESF (enfermeiro, odontólogo, médico, técnico de enfermagem, agentes comunitários de saúde, auxiliar de saúde bucal) e profissionais do Núcleo de Apoio à Saúde da Família - NASF responsáveis por apoio matricial à equipe (fonoaudiólogo, assistente social, terapêutica ocupacional e fisioterapeuta). Um total de 16 sujeitos, sendo 1 (um) do sexo masculino e 15 (quinze) do sexo feminino. Consideraram-se os seguintes critérios de inclusão: profissionais de saúde da ESF e do NASF da Unidade de Saúde supracitada, ser maior de 18 anos e aceitar participar voluntariamente da pesquisa. Foram excluídos da pesquisa os profissionais que não estavam exercendo suas funções (afastados) no período do estudo, por motivos diversos.

Para coleta dos dados, que aconteceu em meados de 2016, foram utilizadas as técnicas de entrevista aberta e diário de campo. 0 áudio das falas foi gravado para posterior transcrição conforme consentimento prévio dos participantes. $\mathrm{O}$ diário de campo registrou acontecimentos e ocorrências importantes durante os momentos da entrevista. Esse recurso complementou a descrição e a reflexão sobre aspectos relevantes, pelo registro de impressões pessoais e de comportamentos contraditórios dos sujeitos pesquisados ${ }^{11}$.

Os dados foram analisados à luz da Análise de Conteúdo, que consiste em um conjunto de técnicas de análise de comunicações às quais visam obter, por meio de procedimentos sistemáticos e objetivos de descrição do conteúdo das mensagens, indicadores (qualitativos ou não) que permitam a inferência de conhecimentos relativos às condições de produção/recepção (variáveis inferidas) dessas mensagens ${ }^{12}$. A análise dos dados aconteceu em três etapas: na primeira, as entrevistas foram transcritas, nomeando codinomes (códigos) aos sujeitos. Na segunda, realizou-se a leitura profunda e exaustiva das entrevistas a 


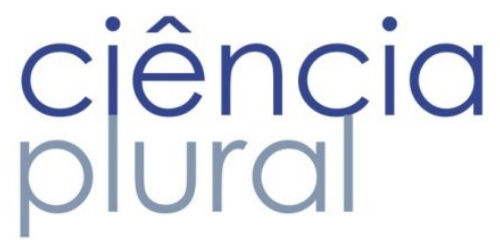

fim de transcender os aspectos da superficialidade. Na terceira etapa, construiu-se um mapeamento (grelha) para facilitação da análise, permitindo a definição final das categorias emergentes a partir das formações identificadas nos discursos dos sujeitos.

No que diz respeito aos aspectos éticos, a investigação foi aprovada pelo Comitê de Ética em Pesquisa do Hospital Universitário Onofre Lopes, da Universidade Federal do Rio Grande do Norte, no parecer $n^{0} 1.535 .358 / 15$, seguindo as Diretrizes e Normas Regulamentadoras para pesquisa envolvendo seres humanos, aprovadas pelo Conselho Nacional de Saúde do Ministério da Saúde, conforme resolução $n^{0} 466 / 12$.

\section{Resultados e Discussão}

Para maior compreensão da interpretação dos dados coletados foi elaborado o seguinte Plano de Análise (Quadro 1) que mostra o surgimento das categorias a partir do material textual.

A análise propriamente dita resultou em quatro categorias empíricas, ilustradas no Quadro 1 e descritas a seguir.

Quadro 1: Plano de Análise, com categorias e subcategorias, emergidas a partir do material textual. Natal-RN, 2016.

\begin{tabular}{|c|c|c|}
\hline & CATEGORIAS & SUBCATEGORIAS \\
\hline \multirow{3}{*}{ 1) } & \multirow{3}{*}{$\begin{array}{l}\text { A percepção dos profissionais sobre } \\
\text { a educação em saúde }\end{array}$} & 1.1)A prevenção de doenças \\
\hline & & 1.2) Informar e educar em saúde \\
\hline & & $\begin{array}{l}\text { 1.2)O desconhecimento da Educação } \\
\text { Popular em Saúde }\end{array}$ \\
\hline \multirow[t]{3}{*}{ 2) } & \multirow{3}{*}{$\begin{array}{l}\text { As práticas de educação em saúde } \\
\text { desenvolvidas para usuários } \\
\text { hipertensos }\end{array}$} & $\begin{array}{l}\text { 2.1) As palestras enquanto principais ações } \\
\text { educativas }\end{array}$ \\
\hline & & 2.2) As práticas educativas na comunidade \\
\hline & & $\begin{array}{c}\text { 2.3) A falta de cronograma e regularidade nas } \\
\text { atividades }\end{array}$ \\
\hline \multirow[t]{2}{*}{ 3) } & \multirow{2}{*}{$\begin{array}{l}\text { Os entraves para o desenvolvimento } \\
\text { das ações de educação em saúde }\end{array}$} & $\begin{array}{l}\text { 3.1) Baixa adesão dos profissionais às } \\
\text { práticas de educação em saúde }\end{array}$ \\
\hline & & 3.2) As agendas profissionais incompatíveis \\
\hline \multirow[t]{2}{*}{ 4) } & \multirow{2}{*}{$\begin{array}{l}\text { A formação de grupos de } \\
\text { autocuidado para portadores de HAS }\end{array}$} & $\begin{array}{l}\text { 4.1) Experiência das equipes com trabalhos } \\
\text { com grupos }\end{array}$ \\
\hline & & $\begin{array}{l}\text { 4.2) Perspectivas e opiniões sobre a } \\
\text { formação de grupos }\end{array}$ \\
\hline
\end{tabular}




\section{ciência plural}

\section{A PERCEPÇÃO DOS PROFISSIONAIS SOBRE A EDUCAÇÃO EM SAÚDE}

Essa categoria teve origem a partir de três núcleos de sentidos: a prevenção de doenças; informar e educar em saúde; e o desconhecimento da Educação Popular em Saúde.

O núcleo "a prevenção de doenças" sinalizou a forma como a educação em saúde é compreendida pelos profissionais entrevistados enquanto um ato voltado quase que exclusivamente para a prevenção de doenças, enfatizando a importância da educação em saúde como uma forma de evitar o adoecimento. As falas seguintes confirmam essa assertiva:

[A educação em saúde] é uma estratégia muito relevante na atenção básica, porque você vai informar a população a respeito dos riscos de contrair as doenças (Profissional 7).

Com a informação, elas podem melhorar. Só não melhora quem não quer, porque se fizer o que é certo, melhora com certeza (Profissional 9).

Através da educação em saúde as pessoas recebem informações sobre a doença delas e aprendem a se tratar melhor (profissional 11).

Estas falas nos apresentam uma visão reducionista e alienante da educação em saúde pelos trabalhadores pesquisados, haja vista a ausência do caráter emancipatório e democrático e a presença marcante das concepções teóricas e metodológicas da chamada educação bancária, em que o processo educativo é resumido ao ato de transmitir informações e conhecimentos aos usuários ${ }^{14}$. Nessa concepção ocorre uma redução no processo educativo, em que o usuário é apenas paciente, na essência da palavra, esperando e recebendo toda a ação desenvolvida exclusivamente pelo ator principal nesse contexto, 0 profissional. Freire ${ }^{15}$ refere que, na educação bancária, em lugar de comunicar-se, o educador faz comunicados e depósitos, enquanto os educandos, recebem pacientemente, memorizam e repetem.

Finalmente, o terceiro núcleo, "o desconhecimento da Educação Popular em Saúde", agregou as narrativas colhidas que remetem ao conhecimento ou desconhecimento da Educação Popular em Saúde (EPS) por parte dos sujeitos da pesquisa. Constatamos que a maioria dos atores envolvidos nesse estudo desconhece a EPS ou tem uma percepção equivocada e/ou reduzida dessa estratégia metodológica.

Não, não sei o que é educação popular em saúde. Na verdade, nunca ouvi falar nisso. (Profissional 1)

Não. Particularmente eu nunca ouvi falar nessa modalidade de educação (Profissional 4). 
Sei não (...). Sinceramente, eu não sei (Profissional 10).

Há que se ressaltar que o processo de formação dos profissionais na área da saúde ainda é pautado fortemente no modelo biomédico tradicional, predominantemente clínico, medicalizante e centrado em procedimentos. A formação é organizada em grades curriculares fechadas (rígidas), o ensino é dividido em conteúdos e organizado de maneira compartimentada, e a busca pela aprendizagem da prática clínica e pela especialidade exacerbada é estimulada ${ }^{16}$. Assim, esse itinerário formativo hegemônico dificulta 0 desenvolvimento de práticas sanitárias construídas coletivamente, mais resolutivas e que englobam a participação social na construção de uma sociedade mais justa, como é o caso da EPS.

Em outras falas dos entrevistados, observamos um pequeno avanço em relação ao entendimento ou à proximidade com a EPS, mesmo que com algumas confusões de sentido ou problemas conceituais. Vejamos:

É o que a gente chama dessas ações educativas. É exatamente você, de certa forma, romper barreiras para levar informação para as pessoas (Profissional 6).

É o saber adquirido ao longo do tempo, pela convivência na sociedade (Profissional 12).

Refere-se à comunicação informal voltada para um grupo específico, o qual facilite a interação entre o profissional e os pacientes (Profissional 14).

Nos depoimentos acima, os entrevistados não apresentam uma discussão mais apurada sobre o tema pesquisado. Parte deles tenta expor um conceito de EPS baseado na semântica das palavras que compõem o nome, e não, através de uma organização de ideias que se tem acerca do tema. As falas que mais se aproximaram, mesmo que minimamente, das discussões e das teorias que compõem a EPS foram as seguintes:

É uma metodologia que trabalha com a população de uma determinada área verificando suas especificidades, ou seja, respeitando as diferenças de cada população (Profissional 15).

Eu acho que é a educação com a participação da população (Profissional 16).

A necessidade de qualificar os trabalhadores de saúde, quando se trata de EPS, é uma importante questão atualmente e um desafio para as Instituições de Ensino Profissionalizantes e Universidades, haja vista a incipiência de políticas de qualificação, no interior do SUS, que assegurem ao conjunto de seus atores capacitação suficiente para o exercício das ações de Educação em Saúde ${ }^{17}$. 


\section{ciência \\ plural}

Percebe-se que os trabalhadores desta ESF demonstraram um conhecimento mínimo e insuficiente sobre a EPS para desenvolver práticas nessa perspectiva metodológica. Portanto, é necessário encontrar os caminhos gerenciais e formativos capazes de permitir que as práticas de saúde possam fluir mais integradas à lógica de vida da população e que se generalizem institucionalmente ${ }^{18}$.

\section{AS PRÁTICAS DE EDUCAÇÃO EM SAÚDE DESENVOLVIDAS PARA USUÁRIOS HIPERTENSOS}

Essa categoria foi alicerçada com base em três subcategorias associadas às práticas de educação em saúde realizadas pela ESF e direcionadas aos usuários hipertensos.

A primeira, "as palestras enquanto principais ações educativas", discute sobre o método utilizado nas práticas de educação em saúde desenvolvidas pela equipe da UBS e direcionadas aos portadores de HAS, agregando as narrativas que demonstram os principais meios utilizados pelos profissionais para realizar essas práticas e destaca a utilização da palestra como método de educação em saúde.

Acontecem palestras explicando situações em que os hipertensos podem levar a vida normalmente, sobre uma rotina melhor para eles. (Profissional 1)

Realizamos ações educativas em cada área, como: palestras, ações diretas com os hipertensos, orientações. São momentos muito ricos. (Profissional 5).

A equipe realiza palestras para informar a população como se deve fazer para evitar doenças e manter uma boa saúde (Profissional 9).

Como podemos observar nestas falas, as palestras foram o principal método de educação em saúde direcionado aos hipertensos pela equipe de ESF. Nesse tipo de método, os participantes são apenas ouvintes, espectadores que não participam ativamente da ação. No final, acreditou-se que isso foi o suficiente para que o aprendizado tenha ocorrido. Porém é importante enfatizar que o simples fato de se estar presente durante o desenvolvimento de uma atividade de educação não quer dizer que se está aprendendo ou construindo conhecimentos, porquanto a construção do conhecimento requer muito mais do que ouvir e memorizar conteúdos e ensinamentos repassados por outras pessoas ${ }^{19}$.

A crítica que se faz a esse método é de que ele só serve para transmitir conhecimentos, receitas prontas e acabadas a serem seguidas pelos ouvintes, o que é insuficiente para efetivar o processo de ensino-aprendizagem. Pode se dizer que a ESF pesquisada desenvolve ações de educação em saúde nos moldes tradicionais, utilizando largamente as palestras para isso. Assim, seus trabalhadores precisam entender que devem ser implantados métodos inovadores nesse âmbito, capazes de estimular formas ativas 


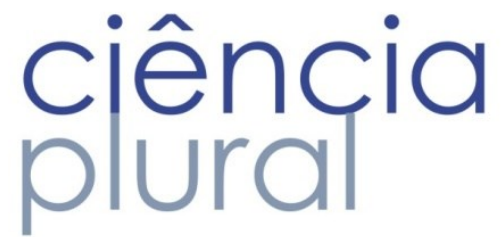

de intercambio social e comunitário, identificando as potencialidades locais e as implicações da HAS nas diversas formas de viver existentes na realidade ${ }^{20,} 21$.

A segunda, "as práticas educativas na comunidade", reúne discursos referentes às ações ditas extramuros, executadas fora da estrutura física da Unidade de Saúde, nas ruas, nos domicílios, nas calçadas, nos espaços públicos e equipamentos sociais da comunidade:

Geralmente é na comunidade mesmo, os agentes de saúde levam o enfermeiro até a área deles, juntam um grupo especifico e faz a palestra (Profissional 1).

Aqui nesse bairro a gente faz ações nas calçadas. A gente vai, a agente comunitária convoca a área dela e alguém cede a sua garagem e a gente faz a ação lá (Profissional 4).

Na maioria das vezes é assim: nós nos reunimos em um local, uma casa, uma garagem, e chamamos os hipertensos e diabéticos daquela área para a palestra (Profissional 11).

Observando essas narrativas, vemos que as práticas de educação em saúde são realizadas, de fato, no seio da comunidade, o que é interessante e salutar, pela necessidade de expandir as ações da equipe para todo o território adscrito e aumentar sua eficácia via conhecimento do próprio meio social e comunitário, das complexidades e das dinâmicas que os rodeiam, onde vivem as pessoas para as quais essas ações são direcionadas, fortalecendo o vínculo entre profissionais e usuários.

Em tempo, é necessário esclarecer que, pelas falas abaixo, o motivo que levou a equipe a desenvolver essas práticas na comunidade foi o insucesso em ações de educação em saúde realizadas antes dentro da unidade, e não, a intenção de aproximar a equipe da realidade da comunidade e aumentar os canais de interação:

No início nós tentamos fazer as reuniões dos grupos aqui mesmo na unidade, mas quase ninguém vinha. Aí, tivemos a ideia de fazer nas áreas dos agentes de saúde, e passamos a fazer em calçadas, em garagens, debaixo de plantas. $A$ adesão tem sido bem melhor (Profissional 3).

Na maioria das vezes, organizamos as palestras por micro áreas porque fica mais fácil para fazer e os pacientes gostam mais do que se for feita aqui na unidade. Quando se faz aqui na Unidade dá poucas pessoas (Profissional 8).

Todas essas exposições sugerem que as ações de educação em saúde verticalizadas, que visaram repassar conceitos e comportamentos e foram feitas em um nível diferente em relação aos dos participantes, não trazem, na maioria das vezes, os resultados esperados e tendem ao fracasso. É nesse aspecto que a 


\section{ciência plural}

EPS avança em relação às práticas tradicionais, pois se mostra mais efetiva e eficiente, ao passo que o seu argumento central é de que a aproximação e a troca de saberes entre a equipe e a comunidade propiciam o compartilhamento de ideias e concepções de vida diferentes, facilitando 0 alcance de práticas educativas efetivas $^{22}$.

Por sua vez, a terceira subcategoria, "a falta de cronograma e regularidade nas atividades", agrega fragmentos dos depoimentos dos sobre a forma de organização das ações de educação em saúde voltadas aos usuários hipertensos. A falta de um cronograma organizado, que mantenha a regularidade das ações de educação em saúde, parece ser um grande problema na realidade pesquisada. A maioria dos trabalhadores entrevistados apontou esse item como algo que traz descontinuidade no processo de educação, o que, por sua vez, diminui sua eficácia e compromete seus resultados:

Sinto falta da periodicidade. Quando tem algum evento, aí chamam a gente. Não é uma coisa rotineira (Profissional 2).

Ás vezes fazemos uma ação e passam vários dias, várias semanas para fazer outra, ai fica complicado (Profissional 11).

Eu acho que a gente poderia ter um calendário regular, para que essas ações fossem realizadas e isso iria fortalecer o vínculo como o grupo (Profissional 6).

É importante não restringir a educação em saúde a momentos pontuais ou ocasiões, porque todos os momentos que envolvem interação com e entre as pessoas usuárias dos serviços de saúde devem ser considerados propícios para desenvolver ações de educação em saúde. Então, não se pode conceber a educação em saúde nem pensar em trabalhá-la apenas em momentos específicos, pois, dessa forma, ela estará sendo reduzida a uma atividade prática pontual, próxima aos moldes tradicionalistas, que não contemplam a complexidade do processo educativo ${ }^{23}$.

\section{OS ENTRAVES PARA O DESENVOLVIMENTO DAS AÇÕES DE EDUCAÇÃO EM SAÚDE}

Essa categoria traz à tona os problemas e as fragilidades mais marcantes das práticas de educação em saúde da empiria e discute sobre elas, representando uma espécie de auto avaliação. Foi referida a baixa adesão dos profissionais às práticas de educação em saúde e as agendas profissionais incompatíveis.

Somos nós do NASF juntamente com a enfermeira e os agentes de saúde. Geralmente somos nós que vamos. Os outros profissionais dificilmente vão (Profissional 4). 
Geralmente quem participa é a enfermeira e nós, agentes de saúde. Algumas vezes que o pessoal do NASF também foi, mas certo mesmo é a gente (Profissional 11).

Analisando as narrativas, fica evidente que os momentos de educação em saúde, na comunidade, ficam, quase sempre, sob a responsabilidade da enfermeira e dos agentes comunitários de saúde da unidade, com o suporte do NASF, que, aparentemente, tem prestado esse suporte através de um rodízio dos profissionais que o compõem. Essa realidade é preocupante, primeiramente pela responsabilização de apenas alguns profissionais para realizar uma tarefa que necessita de múltiplos olhares e contribuições.

Muitas vezes o médico é forçado a atender um total de pacientes para consultas que o impede de participar de qualquer outra coisa (Profissional 7).

Acho que deveria ter a participação de mais profissionais. Mas, para isso acontecer, é preciso que o calendário de atendimento da unidade seja refeito e seja seguido por todos, ai sobraria tempo toda semana para se trabalhar a educação em saúde (Profissional 16).

A incompatibilidade de agendas de trabalho entre eles dificulta e até impede o desenvolvimento de ações educativas que envolvem todos os integrantes da equipe simultaneamente. Isso denota que os trabalhadores dessa equipe não discutem e/ou negociam sobre a organização de suas agendas de trabalho. Pelo que percebemos, cada profissional organiza sua agenda de acordo com suas opiniões e comodidade, sem que a equipe se estruture como um todo para isso.

Quem geralmente participa é a enfermeira e os agentes comunitários de saúde. Os demais quase nunca têm tempo para participar dessas ações (Profissional 8).

O certo era participar toda a equipe, mas você sabe como é, tem profissionais que nunca vão (Profissional 12).

Vários são os condicionantes que envolvem a problemática da pouca adesão/envolvimento dos profissionais às ações de educação em saúde. A necessidade do envolvimento de todos os profissionais da equipe nas atividades comunitárias, de modo geral, e, principalmente, nas atividades de educação em saúde, é capital para que elas prosperem, haja vista os muitos esforços investidos para a realização desses momentos. Quando se desenvolvem atividades com grupo de pessoas, a complexidade dessas atividades exige o empenho e a disponibilidade de todos os interessados, caso contrário, a tendência é de que as ações não prosperem, e o projeto fracasse ${ }^{24}$. 


\section{A FORMAÇÃO DE GRUPOS DE AUTOCUIDADO PARA PORTADORES DE HAS}

\section{ciência \\ plural}

Essa categoria trata da percepção da aplicabilidade da formação de grupos de portadores de HAS na atenção básica visando à promoção do autocuidado. Existe uma fragilidade considerável no tocante ao que permeia o autocuidado, que dificulta sua estimulação por parte deles com os usuários. A maioria dos entrevistados não tem aproximação com as discussões sobre autocuidado, o que pode ser motivado por deficiências na formação e/ou ausência de EPS. Esse fato, provavelmente, está comprometendo o desenvolvimento de práticas sanitárias e de educação em saúde que promovam a corresponsabilização dos usuários em seus processos de saúde-doença:

Não sei ao certo o que é autocuidado. Isso nunca foi discutido na minha formação (Profissional 8).

Nunca estudei isso e também nunca tivemos estudos sobre isso (Profissional 11).

Porém, alguns dos profissionais entrevistados conseguiram demonstrar certa proximidade, mesmo que ainda com uma visão minimizada do que permeia o conceito de autocuidado. Na fala deles, há um pouco do que seria a prática do autocuidado: as atividades que os indivíduos desempenham de forma deliberada em seu próprio benefício, com o propósito de manter a vida, a saúde e o bem-estar ${ }^{23}$. Assim, estimular a comunidade para desenvolver práticas de autocuidado deve ser uma tarefa constante das equipes de ESF, nas mais variadas áreas, tanto para as pessoas que estão equilibradas em seu processo saúde-doença quanto para as que não estão.

São cuidados voltados para si mesmo. Tipo assim, a capacidade da pessoa se cuidar (Profissional 12).

Acho que é a pessoa ser responsável por cuidar de si próprio, cuidar de si mesmo (Profissional 13).

São pessoas orientadas a cuidar de sua saúde, responsáveis pelo seu próprio bem estar (Profissional 14).

O trabalho com grupos de pessoas tende a quebrar a relação vertical historicamente construída entre o profissional e o usuário e os aproxima, o que facilita o processo de educação em saúde ${ }^{13}$. Durante as entrevistas, os profissionais apresentaram suas vivências e, principalmente, as da equipe, e mencionaram os trabalhos exitosos que desenvolvem com grupos de pessoas demonstrando que os resultados são animadores, na visão da própria equipe. 


\section{ciência \\ plural}

A gente tem e já faz. Tem o grupo de tabagismo aqui e pensamos ainda em criar um de controle de obesidade. Trabalhando nesses dois grupos, estaremos automaticamente trabalhando o controle da hipertensão arterial (Profissional 3).

Nós temos um grupo de gestantes e o NASF tem um grupo de tabagismo. Dá muito resultado. Muitas pessoas já pararam de fumar e outras já diminuíram muito o vício (Profissional 13).

A estratégia do trabalho em grupo para a educação em saúde facilita a exposição e a discussão dos principais problemas e necessidades de saúde dos participantes e possibilita o compartilhamento e a sugestão de possibilidades para resolver ou minimizar as questões apresentadas. Tudo isso é feito através da troca de experiências e da construção de novos saberes, com base não somente nas indicações trazidas pelos profissionais de saúde, mas também em outros usuários que enfrentam problemas semelhantes ${ }^{13}$. Nesse sentido, a estratégia de formação de grupos na atenção básica pode ser uma ferramenta poderosa no combate à dominação exercida pelos serviços de saúde, com atividades educativas que se limitam a transferir informações com caráter coercitivo e traços de autoridade e dominação ${ }^{6}$.

Alguns sujeitos têm uma visão mais ampla da formação de grupos e das potencialidades desse método nas atividades de educação em saúde com a população. A interação entre a equipe de saúde e 0 usuário e a possibilidade de haver trocas de experiências entre os participantes foram pontos abordados pelos entrevistados que demonstram uma aproximação de sua visão com as práticas inovadoras e contra hegemônicas de educação em saúde:

$\mathrm{Na}$ troca de experiências, quando você vai falar com um grande grupo, sempre tem alguém que acrescenta algo, naquele momento, dentro da sua realidade $e$ que pode ser a realidade do outro (Profissional 6).

A troca de experiências motiva o outro a aderir ao desafio da dieta, a prática de exercícios, a tomar os remédios. As atividades em grupo ajudam a quebrar as barreiras nas informações e ajuda na interação da comunidade com a gente $e$ entre ela mesma (Profissional 14).

Mesmo com todas as potencialidades mencionadas acerca da formação de grupos, ainda existem muitos profissionais que não acreditam nesse método como uma boa alternativa para o desenvolvimento de ações de educação em saúde e são resistentes a ele, como podemos observar na fala a seguir: 


\section{ciência \\ plural}

A informação em educação em saúde é muito precária, então se você tivesse um acesso de forma individualizada a cada pessoa, seria bem mais eficaz (Profissional 3).

É visível a resistência do profissional sobre a formação de grupos pela atenção básica. Ao se posicionar dessa forma, o profissional demonstra uma opinião pautada na educação em saúde tradicional, em que se acredita que as ações individuais são mais eficientes do que as atividades coletivas. Esse posicionamento é fruto de uma formação acadêmica compartimentalizada, demasiadamente clínica e focada em procedimentos individuais.

Freire $^{7}$ considerou 0 aprendizado com grupos como sendo muito mais rico, participativo, emancipatório e cidadão do que o individual, pois esse tem como propósito uma vivência participativa com ênfase no diálogo, estimulando a participação de todos. Os círculos extrapolam o aprendizado individual, produzindo também modos próprios e renovados, solidários e coletivos de pensar ${ }^{25}$. Este enfoque trabalha com a perspectiva de que educadores e educandos possam potencializar a luta pela qualidade de vida, fortalecer movimentos de participação popular transformadores, a partir de uma ecologia de saberes.

\section{Considerações Finais}

As mudanças de vida das pessoas têm provocado o aparecimento de doenças crônicas e degenerativas, como a Hipertensão Arterial Sistêmica. Certamente um dos motivos pelos quais as ações educativas não vêm dando os resultados esperados é o fato de estarem atreladas ao desenvolvimento de práticas em saúde nos moldes tradicionais, que precisam ser mais efetivas, em serviços de saúde acessiveis, resolutivos e centrados nos sujeitos.

O estudo não esclareceu adequadamente os aspectos operacionais das atividades educativas desenvolvidas nos grupos do cenário empírico, entretanto o material analisado sugere que elas se aproximaram das ações de educação em saúde mais tradicionais. Todavia, independentemente disso, reafirmamos a importância de fazer atividades com grupos de usuários que tenham como objetivo 0 desenvolvimento do pensamento crítico a respeito do seu meio social e suas condições de vida e saúde.

É lícito destacar que a Educação Popular em Saúde se propõe a trabalhar com a totalidade das dimensões do sujeito para o desenvolvimento de novas relações, através da compreensão das contradições estruturais da sociedade e a diversidade das culturas, o compromisso com processos democráticos de luta pela emancipação das pessoas e a organização dos movimentos populares, o planejamento coletivo, a construção compartilhada de saberes, a interação, a comunicação e a mediação dos conflitos do grupo, 0 


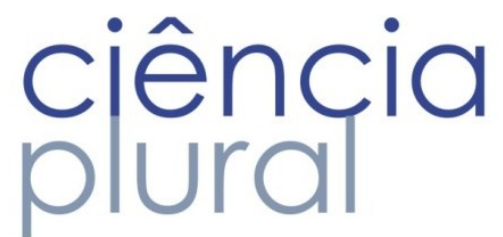

empoderamento, o protagonismo e a satisfação dos usuários com as práticas de cuidado, a ampliação dos direitos e o controle social.

A prática educativa libertadora, aliada à formação de grupos de pessoas visando ao autocuidado, pode se configurar como uma estratégia de grande envergadura no desenvolvimento de um serviço de saúde capaz de intervir criticamente no mundo, respeitando os princípios da cidadania e da democracia.

\section{Referências}

1. Brasil. Ministério da Saúde. Secretaria de Atenção à Saúde. Departamento de Atenção Básica. Estratégias para o cuidado da pessoa com doença crônica. Brasília: Ministério da Saúde; 2014. (Cadernos de Atenção Básica, n. 35).

2. Santos JC, Moreira TMM. Fatores de risco e complicações em hipertensos/diabéticos de uma regional sanitária do nordeste brasileiro. Rev. esc. enferm. USP. 2012. 46(5):1125-1132. http://dx.doi.org/10.1590/S0080-62342012000500013.

3. Reis SM, Ferreira VRF, Prado FL, Lopes AMC. Análise da resposta pressórica mediante exercício físico regular em indivíduos normotensos, hipertensos e hipertensos-diabéticos. Rev. bras. cardiol. (Impr.). 2012. 25(4):90-298.

4. Brasil. Vigitel Brasil 2011: Vigilância de Fatores de Risco e Proteção para Doenças Crônicas por Inquérito Telefônico. Brasília: Ministério da Saúde, 2012.

5. Almeida ER, Moutinho CB, Leite MTS. A prática da educação em saúde na percepção dos usuários hipertensos e diabéticos. Saúde debate. 2014;38(101): 328-337. http://dx.doi.org/10.5935/01031104.20140030.

6. Maffacciolli R, Lopes MJM. Os grupos na atenção básica de saúde de Porto Alegre: usos e modos de intervenção terapêutica. Ciênc. saúde coletiva. 2011. 16(Suppl 1):973-982. http://dx.doi.org/10.1590/S141381232011000700029 .

7. Freire P. Pedagogia da esperança: um reencontro com a pedagogia do oprimido. $3^{\mathrm{a} e d .}$ Rio de Janeiro: Paz e Terra; 1992.

8. Brasil. Ministério da Saúde. Estratégias para o cuidado da pessoa com doença crônica: hipertensão arterial sistêmica. Brasília: Ministério da Saúde, 2013. (Cadernos de Atenção Básica, n. 37).

9. Minayo MCS, Diniz D, Gomes R. O artigo qualitativo em foco. Ciênc. saúde coletiva. 2016. 21(8):23262326. http://dx.doi.org/10.1590/1413-81232015218.15592016..

10. IBGE, 2015. IBGE. Instituto Brasileiro de Geografia e Estatística. Disponível em: <http://www.ibge.gov.br>. Acesso em: 13 jul. 2016.

11. Minayo MCS. O desafio do conhecimento: pesquisa qualitativa em saúde. 14ed. São Paulo: Hucitec, 2014.

12. Bardin L. Análise de conteúdo. Ed. 70: Lisboa; 1997.

13. Souza AC, Colomé ICS, Costa LED, Oliveira DLC. A educação em saúde com grupos na comunidade: uma estratégia facilitadora da promoção da saúde. Rev Gaúcha Enferm. 2005; 26(2):147-53. 


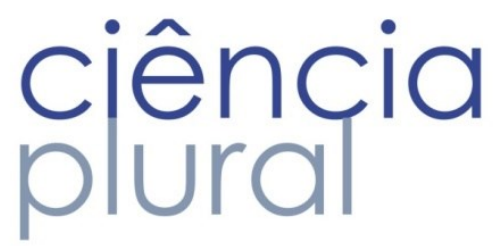

14. Pereira AKAM, Rodrigues MP, Silva GSN, Vieira-Meyer APF, Alves RS. Concepções e práticas de profissionais de nível superior em educação em saúde na estratégia saúde da família. Trabalho, Educação e Saúde. 2015. 13(Suppl. 2),131-152. https://dx.doi.org/10.1590/1981-7746-sip00085

15. Freire P. Pedagogia do Oprimido. 50ed. Rio de Janeiro: Paz e Terra; 2011.

16. Silva CF, Miranda MGO, Saraiva AKM. O compromisso político que permeia a formação em enfermagem: o estágio em questão. Rev enferm UFPE online. 2016; 10(9):3275-83.

17. Amaral MCS, Pontes AGV, Silva JV. O ensino de Educação Popular em Saúde para o SUS: experiência de articulação entre graduandos de enfermagem e Agentes Comunitários de Saúde. Interface (Botucatu). 2014; 18(Suppl 2):1547-1558. http://dx.doi.org/10.1590/1807-57622013.0441.

18. Vasconcelos EM. Educação popular: de uma prática alternativa a uma estratégia de gestão participativa das políticas de saúde. Physis. 2004; 14(1):67-83. http://dx.doi.org/10.1590/S010373312004000100005

19. Vygotsky LS. A formação social da mente. São Paulo: Martins Fontes, 1984.

20. Souza CS, Iglesias AG, Pazin-Filho A. Estratégias inovadoras de ensino-aspectos gerais. Medicina (Ribeirão Preto). 2014; 47(3):284-92.

21. Torres HC, Franco LJ, Stradioto MA, Hortale VA, Schall VT. Avaliação estratégica de educação em grupo e individual no programa educativo em diabetes. Rev. Saúde Pública. 2009; 43(2):291-298. http://dx.doi.org/10.1590/S0034-89102009005000001.

22. Flisch TMP, Alves RH, Almeida TAC, Torres HC, Schall VT, Reis DC. Como os profissionais da atenção primária percebem e desenvolvem a Educação Popular em Saúde?. Interface (Botucatu). 2014; 18(Suppl 2):1255-1268. http://dx.doi.org/10.1590/1807-57622013.0344.

23. Salci MA, Maceno P, Rozza SG, Silva DMGV, Boehs AE, Heidemann ITSB. Educação em saúde e suas perspectivas teóricas: algumas reflexões. Texto contexto - enferm. 2013; 22(1):224-230. http://dx.doi.org/10.1590/S0104-07072013000100027.

24. Vasconcelos EM. Educação popular e a atenção à saúde da família. 5ed. São Paulo: Hucitec; 2010.

25. Brandão, CR. O que é o método Paulo Freire. 7ed. São Paulo: Brasiliense; 2005. 